\title{
The Politics of Public Good Provision: Evidence from Indian Local Governments*
}

\author{
Timothy Besley ${ }^{\dagger} \quad$ Rohini Pande Lupin Rahman $^{\ddagger}$ \\ Vijayendra Rao
}

\begin{abstract}
This paper uses village and household survey data from South India to examine how political geography and politician identity impacts on public good provision. We provide evidence that the nature of this relationship varies by type of public goods. For high spill-over public goods residential proximity to elected representative matters. In contrast, for low spill-over public goods sharing the politician's group identity is what matters.
\end{abstract}

\section{Introduction}

Making the state more relevant to the interests of the poor is an increasingly important theme in discussions of anti-poverty policies. Yet there is little consensus on the appropriate way to develop governance structures that are responsive to the interests of the poor. Whether greater decentralization of political power can achieve this remains unclear. On the one hand, it may enhance the accountability of elected representatives and amplify the political voice of poor people while, on the other, it may enhance the influence of local elites (Bardhan and Mookherjee (2000)) Moreover, whether decentralized public good provision better represents the needs of the local population remains sensitive to assumptions about heterogeneity of preferences in the local population and extent of spill-overs associated with different public goods (Besley and Coate (2003)).

\footnotetext{
*We thank Ian Gascoigne for research assistance.

${ }^{\dagger}$ London School of Economics

${ }^{\ddagger}$ Yale University

${ }^{\S}$ IMF and London School of Economics

ॠWorld Bank
} 
This paper uses survey data on village governments in South India to provide some evidence on these issues. In India, a 1993 constitutional amendment made a three-tier elected local government obligatory throughout the country. ${ }^{1}$ Our focus is on the lowest tier of this local self-government. This is a popularly elected village council - the Gram Panchayat (from now on, GP). The constitutional amendment also required state governments to delegate certain policy-making powers to these local governments. The specific choice of these policies was left up to states. States have typically delegated responsibility for the construction and maintenance of village public goods and beneficiary selection for various central and state-funded welfare schemes to these bodies (see Chaudhuri (2003) for an overview of the diverse experience of Indian states).

The Indian decentralization experiment is unique on many fronts - of main interest to us are the facts that it mandated political representation via reservation for socially and economically disadvantaged groups and gave representatives elected by villagers decision-making power over an array of village-level public goods. ${ }^{2}$

We focus on reservation for the post of the head of the GP in favor of scheduled castes/scheduled tribes (SC/ST). SC/STs include castes and tribes which have historically suffered economic and social discrimination. ${ }^{3}$ In GPs where the post is reserved for SC/STs only SC/ST individuals can stand for election. The composition of the electorate is unaffected by political reservation.

Previous work on political reservation suggests that political reservation for a group leads to a higher incidence of policies preferred by and/or targeted towards that group (see Pande (2003) for state-level evidence in the case of SC/ST, and Chattopadhyay and Duflo (2002) for village-level evidence in the case of women). Our contribution is to point to the importance of public good technology and political geography in shaping the policy impact of political reservation.

The head has the ability to shape resource allocation, and hence may do so in a direction that favors his own village. How village members benefit from this depends on the technology of the public good. With high spill-over public goods such as the access road to a village or an overhead tank for water, the whole village benefits. However, for low spill-over goods such as

\footnotetext{
${ }^{1}$ The three tiers are defined at different administrative levels with the village being the lowest, then the block and finally the district.

${ }^{2}$ As expenditure levels of village governments are largely set by state governments our main focus is on distribution.

${ }^{3}$ see Pande (2003) for a description of which castes/tribes belong to these categories
} 
programs targeted towards specific groups within the villages, it is less clear. We may expect this to depend on the underlying preferences and sympathies of the head.

Our analysis incorporates insights from the local public finance literature - this concerns the allocation of public spending across geographical units within a polity. In the well-known Weingast, Shepsle, Johnsen (1980) model, the problem is to allocate pure local public goods to a variety of districts, each of whose interest is represented by a legislator. They propose that resource allocation will obey a "norm of universalism" in which each district gets what they want as long as all other districts are allowed to do the same. In their model, there is excessive spending, but the allocation is equal. This contrasts with agenda setting models of resource allocation where the propose is able to get an advantage in getting his/her preferred outcome (see Romer and Rosenthal (1978)) or a minimum winning coalition model in which the winning group is able to get an outcome that it favors (see Baron (1993)). Our findings suggest that agenda setting models can better explain public good allocation in South Indian villages.

This paper fits into a wider literature studying the social and political context of public spending. A variety of studies place weight on the relationship between heterogeneity and public goods provision - see, for example, Alesina, Baqir and Easterly (1999) and Miguel and Gugerty (2002). It is also related to the large literature on political determinants of resource allocation, see for example, Knight (2003).

The remainder of the paper is organized as follows. In the next section, we describe the institutional setting. In section three, we discuss a simple model which motivates our results. Section four we describe our survey and present results. Section five concludes.

\section{Institutional background}

The GP is the lowest tier of local self-government in India and is a popularly elected village council. Depending on village population, a GP may cover between 1 and 5 revenue villages. Every GP consists of up to twenty wards. ${ }^{4}$ Elections are at the ward-level, and the elected ward members constitute the GP council. The head of this council is the Pradhan. ${ }^{5}$

The 73rd constitutional amendment mandated political reservation in

\footnotetext{
${ }^{4}$ For our sample states the population per ward varies between 300 and 800 .

${ }^{5}$ In Andhra Pradesh and Tamil Nadu the Pradhan is directly elected, while in Karnataka he/she is nominated from the pool of elected ward members.
} 
favor of SC/ST for the Pradhan position, and required that the extent of such reservation in a state reflect the $\mathrm{SC} / \mathrm{ST}$ population share in that state. The amendment also required that no GP be reserved for the same group for two consecutive elections. The choice of which GPs to reserve was left to individual states. Typically, the same fraction of GPs are reserved in every district in a state.

A GP has responsibilities of civic administration with limited independent taxation powers. ${ }^{6}$ While the ambit of GP policy influence varies across Indian states GPs typically perform (at least) two distinct policy tasks. The first is beneficiary selection for central and state welfare schemes. These are schemes which provide beneficiary households with funds to acquire household public goods such as housing and private electricity and water supply. Eligibility for these schemes is usually restricted to households below the official poverty line. In addition, most schemes require that a minimum fraction of beneficiaries be SC/ST. The second area of GP policy activism is the construction and maintenance of village public goods such as streetlights, roads and drains. The GP decides the distribution of these public goods within the village, and the quality of such public good provision. ${ }^{7}$

Panchayat legislation requires that the Pradhan consult with villagers (via village meetings) and ward members in deciding the choice of beneficiaries and allocation of public goods. However, final decision-making powers in a GP are vested with the Pradhan.

\section{Theory}

We start with a theoretical model which is intended to think through the issues. ${ }^{8}$ Consider a GP comprising of two villages indexed $j \in\{1,2\}$. Each village has two caste groups indexed $k \in\{s, n\}$, where $s$ denotes the SC/ST group and $n$ the non SC/ST group. The share of group $s$ in village $j$ is $\pi^{j}$.

For simplicity, assume a single public good is provided to each group within a village. Let $g_{k}^{j} \in[0, G]$ denote the level of public good provision for caste $k$ in village $j$. This public good may have positive spill-overs for villagers belonging to the other caste group, $-k$. Hence individuals (potentially) care about the level of public goods provided to both caste groups in a village. Specifically:

\footnotetext{
${ }^{6}$ On average, roughly 10 percent of a GP's total revenue come from own revenues with the remainder consisting of transfers from higher levels of government.

${ }^{7}$ Schedule XI of the Constitution defines the functional items for which states may devolve responsibility to Panchayats.

${ }^{8}$ The model is very similar in many respects to Besley and Coate (2003).
} 


$$
V_{k}^{j}\left(g_{k}^{j}, g_{-k}^{j}\right)=\log \left(g_{k}^{j}\right)+\lambda \log \left(g_{-k}^{j}\right)+y_{k}^{j}
$$

$\lambda \geq 0$ measures the extent of spill-overs in public good provision. Private goods are captured in the term $y_{k}^{j}$. If $\lambda=1$, then it is a pure village-level public good, while if $\lambda=0$, then the good only benefits the group to whom it is provided.

Public goods are funded from a fixed pot of tax revenue, $T$. We normalize the price of public good provision to one. Thus, the budget constraint is:

$$
g_{s}^{1}+g_{s}^{2}+g_{n}^{1}+g_{n}^{2}=T .
$$

Group-wise allocation of public goods is determined by elected GP representatives. Each village elects one villager as representative, one of whom is the Pradhan. We adopt the convention that village one is the Pradhan's village, that is it has the Pradhan as the representative. The GP is reserved if only $\mathrm{SC} / \mathrm{ST}$ individuals can run for election in village 1. For expositional ease we assume that, absent reservation, SC/ST individuals never run for election. ${ }^{9}$ We do not explicitly model the decision making procedure but assume that it maximizes a weighted sum of the utility of the two representatives where a weight $\mu>1 / 2$ is applied to the utility of the Pradhan. Let $\ell(j) \in\{s, n\}$ be the type of the Panchayat representative in village $j$. Then, the public good allocation will solve:

$$
\begin{aligned}
& \mu V_{\ell(1)}^{1}\left(g_{\ell(1)}^{1}, g_{-\ell(1)}^{1}\right)+(1-\mu) V_{\ell(2)}^{2}\left(g_{\ell(2)}^{2}, g_{-\ell(2)}^{2}\right) \\
& \text { subject to } \\
g_{s}^{1}+g_{s}^{2}+g_{n}^{1}+g_{n}^{2}= & T
\end{aligned}
$$

It is easy to check that the solution to this is:

$$
\begin{array}{cc}
g_{\ell(1)}^{1}=\frac{\mu}{1+\lambda} T & g_{-\ell(1)}^{1}=\frac{\mu \lambda}{1+\lambda} T \\
g_{\ell(2)}^{2}=\frac{(1-\mu)}{1+\lambda} T & g_{-\ell(2)}^{2}=\frac{(1-\mu) \lambda}{1+\lambda} T .
\end{array}
$$

Thus the village/caste group allocation depends on the decision-making process as represented by $\mu$ and the extent of spill-overs in public good provision as represented by $\lambda$. Comparison of the public good level across groups yields the following empirically testable predictions.

\footnotetext{
${ }^{9}$ This assumption is in line with reality - Chattopadhyay and Duflo (2003) show that this can be explained by the minority group having higher costs of running for election, while Pande (2003) shows that this can also be explained by inadequate minority representation in political parties.
} 
Claim 1 Pradhan effects - Relative to non-Pradhan village, public good allocation is higher in Pradhan's village.

Claim 2 Caste effects - Relative to non SC/ST group, the public good allocation for the $S C / S T$ group is higher when the GP is reserved.

Claim 3 Spill-overs - The impact of reservation on public good allocation diminishes as spill-overs increase.

\section{Evidence}

In this section we use survey data from India to provide evidence on the impact of Pradhan residence and political reservation on the provision of low and high spill-over public goods.

\subsection{Data and Survey Design}

Our data comes from a survey we conducted in three South Indian states Andhra Pradesh, Karnataka and Tamil Nadu - between September-November 2002. At this point at least one year had lapsed since the last GP election in each of our sample states. ${ }^{10}$ The survey covered 396 villages across 181 GPs in thirty blocks (a block is the administrative unit below a district in a state). ${ }^{11}$ Summary statistics are provided in Table 1 (for details of the survey, see Besley, Pande, Rahman and Rao (2003)).

We use information from an independent audit of village facilities to construct an index of GP activity on high spill-over (i.e. village-level) public goods. This index measures whether the GP undertook any construction or improvement activity on within-village roads, drains, street-lights and water sources since the last GP election. The index is normalized to lie between 0 and 1 . Roughly $79 \%$ of our sample villages experienced GP activism on at least one of these public goods.

We use data from household surveys in a random sub-sample of 193 villages to measure the provision of low spill-over (household) public goods. In every sampled village twenty one household surveys were conducted, of

\footnotetext{
${ }^{10}$ The second round of GP elections in these states occurred in August 2001 in Andhra Pradesh, February 2000 in Karnataka, and October 2001 in Tamil Nadu.

${ }^{11}$ The survey was also conducted in Kerala. Kerala, however, has a different administrative structure - for instance, a Kerala Gram Panchayat covers a population of 30,000 as against $5-10,000$ in the other states.
} 
which four were with SC/ST households and one was with an elected Panchayat representative. ${ }^{12}$ This gives us a total of 4059 households of which 981 were SC/ST. We measure a household's exposure to low spill-over public goods by a dummy which equals one if it had a house or toilet built under a government scheme or if it received a private water or electricity connection via a government scheme since the last GP election. Approximately $7 \%$ of the sample households fall in this category.

We are interested in the implications of political reservation and Pradhan proximity for the allocation of high and low spill-over public goods across and within villages. We capture a village's reservation status by a dummy variable which equals one if the village belongs to a GP reserved for SC/ST. We use two dummy variables to measure the political influence of a village - the first equals one if the Pradhan resides in that village, and the second equals one if the GP headquarters are in that village.

\subsection{Household Level Evidence}

Let $y_{i v g}$ be an indicator variable which equals one if household $i$ in village $v$ in GP $g$ has received a low spill-over public good since the last GP election. We estimate a regression of the form:

$$
y_{i v g}=\alpha_{v}+\gamma_{1} C_{i v g}+\gamma_{2} C_{i v g} \times R_{g}+\gamma_{3} C_{i v g} \times P_{v g}+\gamma_{4} C_{i v g} \times G_{v g}+\phi X_{i v g}+\varepsilon_{i v g}
$$

where $C_{i v g}$ is a SC/ST dummy, $R_{g}$ the SC/ST reservation dummy and $P_{v g}$ and $G_{v g}$ the Pradhan's village and GP headquarter dummies respectively. $\alpha_{v}$ are village fixed effects and $X_{i v g}$ is a set of household level controls (see notes to Table 2 for details). Inclusion of a village fixed effect implies that we identify the effect of reservation on public good provision solely from within village variation in allocation.

The results are in Table 2, columns (1) through (4). In column (1) we see that, in line with scheme guidelines, household public goods are targeted towards SC/ST households - on average, a SC/ST household is 6 percent more likely to receive such a public good. In column (2) we find that the extent of such targeting is enhanced by living in a reserved GP. Relative to living in a non-reserved GP, living in a reserved GP increases a SC/ST

\footnotetext{
${ }^{12}$ An additional household survey was conducted with the Pradhan if s/he resided in that village, and with a ward member otherwise (in six villages both a ward member and Pradhan interview were conducted).
} 
household's likelihood of getting such a public good by 7 percentage points. Columns (3) and (4) demonstrate that this effect is robust to including interactions with Pradhan village and GP headquarter, and that neither interactions are significant. This suggests that enhanced targeting of SC/ST households only comes from reservation.

\subsection{Village Level Evidence}

We now turn to the determinants of village-level allocation of public goods. Our model suggests that overall, relative to non-Pradhan villages, the Pradhan's village will be allocated more public goods. The difference in allocation will, however, vary by type of public good. In the case of low spill-over public goods we will expect higher provision of public goods in Pradhan village if the GP is reserved for $\mathrm{SC} / \mathrm{ST}$, and lower otherwise. As the spillovers associated with the public good increase the difference between levels of provision in reserved and non-reserved Pradhan villages should diminish. For high spill-over public goods, irrespective of GP reservation status, we should observe higher allocation in Pradhan's village.

To examine these predictions we turn to a village-level analysis. First, to examine the village-level determinants of household public good incidence we recover the village fixed effects from (1) and regress these on village characteristics. Second, to examine the determinants of high spill-over public goods we use our index of GP activism on village public goods. ${ }^{13}$.

Our empirical model for village level regressions is:

$$
y_{v g}=\alpha_{b}+\gamma_{1} R_{g}+\gamma_{2} P_{v g}+\gamma_{3} G_{v g}+\gamma_{4} R_{g} \times P_{v g}+\phi X_{v g}+\varepsilon_{v g}
$$

where $\alpha_{b}$ are block dummy variables and $X_{v g}$ are village level controls. These regressions rely on within-block variation in the explanatory variables for identification purposes.

In our household-level regressions (columns (1)-(4)) the village fixed effects were jointly significant. In columns (5) and (6), Table 2 we examine whether village level measures of political power underlie the statistical significance of the village fixed effects. However, none of our measures of political power - whether the Pradhan position is reserved for SC/ST, whether it is the Pradhan's village and/or GP headquarters - affects village-level allocation of household public goods. Household public goods have low spill-overs and are targeted towards SC/ST. Hence we expect non-SC/ST and SC/ST

\footnotetext{
${ }^{13}$ As the public good audit was conducted in every village while household surveys were conducted in only half the villages we have twice as many observations in the latter case
} 
Pradhans' to differ in their propensity to allocate resources towards such public goods. Given this, it is unsurprising that the overall incidence of targeted public goods is unrelated to Pradhan's residence. However, it is surprising that this is also the case when the Pradhan position is reserved for SC/ST. It appears that political reservation is relevant for within-village allocation of low spill-over goods but not for overall village allocation.

Columns (7) and (8) consider the village incidence of high spill-over public goods, as measured by the GP activism index. We find that this index is, on average 0.04 points, higher in the Pradhan's village. In term's of our theory, this underlines our assumption that $\mu$ exceeds one half - so that the Pradhan enjoys agenda setting power in resource allocation. Moreover, the fact that these public goods are high spill-over is consistent with the finding that the reservation status of the GP does not affect the extent of village-level provision. ${ }^{14}$

\section{Concluding Remarks}

This paper takes a preliminary look at resource allocation by elected village governments using data from three Indian states. We motivated the empirical analysis with a simple model of resource allocation based on three aspects - the effect of Pradhan's group identity on policy, the agenda setting powers of the Pradhan and the extent of spill-overs associated with different types of public goods. The evidence speaks to the relevance of these ideas. The results add to a growing body of evidence which looks at decision making at the local level and its impact on the well-being of the poor. However, much remains to be done to gain a complete picture of democracy works in low income contexts.

\footnotetext{
${ }^{14}$ While the effect of being in the Pradhan's village is interesting, we cannot rule out the possibility that the Pradhan's village is politically powerful for reasons other than having the Pradhan.
} 


\section{References}

[1] Alesina, Alberto, Reza Baqir and William Easterly, "Public Goods and Ethnic Divisions," Quarterly Journal of Economics, 114(4), 1243-1284.

[2] Bardhan, Pranab and Dilip Mookherjee, [2000], "Capture and Governance at Local and National Levels," in American Economic Review, Papers and Proceedings.

[3] Baron, David P., [1993], "Government Formation and Endogenous Parties," American Political Science Review; 87(1), 34-47.

[4] Besley, Timothy and Stephen Coate, [2003], "Centralized versus Decentralized Provision of Local Public Goods: A Political Economy Analysis," Journal of Public Economics; 87(12), 2611-2637.

[5] Besley, Timothy, Rohini Pande, Lupin Rahman and Biju Rao, [2003] "Decentralization in India: A Survey of South Indian Panchayats", typescript, LSE.

[6] Chattopadhyay, Raghabendra and Esther Duflo, [2001], "Women as Policy Makers: Evidence from a India-Wide Randomized Policy Experiment," working paper MIT.

[7] Chaudhuri, Shubham, [2003], "What difference does a constitutional amendment make? The 1994 Panchayati Raj Act and the attempt to revitalize rural local government in India," typescript, Columbia University.

[8] Knight, Brian, [2003], "Parochial Interest and the Centralized Provision of Local Public Goods: Evidence from Congressional Voting on Transportation Projects," NBER working paper 9748, forthcoming in the Journal of Public Economics.

[9] Miguel, Ted and Mary Kay Gugerty [2002], "Ethnic Diversity, Social Sanctions and School Funding in Kenya", typescript, Berkeley.

[10] Oates, Wallace, [1972], Fiscal Federalism, Harcourt Brace: New York.

[11] Pande, Rohini, [2000], "Minority Representation and Policy Choices: The Significance of Legislator Identity," American Economic Review; 93(4), 1132-1151. 
[12] Romer, Thomas and Howard Rosenthal, [1978], "Political Resource Allocation, Resource Allocation and the Status Quo," Public Choice, 33, $27-43$.

[13] Weingast, Barry, Kenneth Shepsle, and C. Johnsen, [1981], "The Political Economy of Benefits and Costs: A Neo-classical Approach to Distributive Politics," Journal of Political Economy, 89, 642-64. 
TABLE 1: Summary Statistics

\begin{tabular}{|c|c|c|}
\hline Household Level Data & Mean & S.d. \\
\hline Targeted Schemes & 0.072 & {$[0.258]$} \\
\hline SC/ST Household & 0.242 & {$[0.428]$} \\
\hline SC/ST Household*Pradhan reserved for SC/ST & 0.066 & {$[0.248]$} \\
\hline SC/ST HouseholdPradhan Village & 0.098 & {$[0.297]$} \\
\hline SC/ST Household*GP headquarters & 0.074 & [0.261] \\
\hline Muslim & 0.044 & {$[0.205]$} \\
\hline Christian & 0.009 & {$[0.096]$} \\
\hline Elected Officials' Household & 0.049 & {$[0.216]$} \\
\hline SC/STElected Officials' Household & 0.010 & {$[0.100]$} \\
\hline Proportion Landless & 0.312 & [0.463] \\
\hline Age of Household Head & 48.001 & [14.623] \\
\hline Whether Household Head Literate & 0.636 & [0.481] \\
\hline Household Size & 5.336 & [2.386] \\
\hline Proportion Household Farmers & 0.673 & [0.469] \\
\hline \multicolumn{3}{|l|}{ Village Level Data } \\
\hline Non-Targeted Schemes & 0.443 & {$[0.315]$} \\
\hline Proportion SC/ST Households & 0.298 & {$[0.255]$} \\
\hline Pradhan Village & 0.421 & [0.494] \\
\hline Pradhan reserved for SC/ST & 0.210 & {$[0.408]$} \\
\hline Pradhan Village*Pradhan reserved for SC/ST & 0.094 & [0.292] \\
\hline GP headquarters & 0.367 & [0.482] \\
\hline Log Total Population & 7.266 & [0.971] \\
\hline Log Village Area & 6.375 & {$[0.978]$} \\
\hline Proportion Area Irrigated & 0.137 & {$[0.150]$} \\
\hline Proportion Landless & 0.304 & {$[0.248]$} \\
\hline Literacy Rate & 0.342 & {$[0.133]$} \\
\hline Distance From Nearest Town & 19.435 & [15.612] \\
\hline Male Agricultural Wage Rate & 48.023 & [11.950] \\
\hline
\end{tabular}


TABLE 2: Effect of SC/ST Reservation on resource allocation

\begin{tabular}{|c|c|c|c|c|c|c|c|c|}
\hline & \multicolumn{6}{|c|}{ Household public goods } & \multirow{2}{*}{\multicolumn{2}{|c|}{$\begin{array}{c}\text { Village public goods } \\
\text { Village level }\end{array}$}} \\
\hline & \multicolumn{4}{|c|}{ Household regression } & \multicolumn{2}{|c|}{ Village fixed effect } & & \\
\hline & $(1)$ & $(2)$ & $(3)$ & $(4)$ & $(5)$ & $(6)$ & $(7)$ & $(8)$ \\
\hline \multirow[t]{2}{*}{ SC/ST Household } & $0.066^{* * *}$ & $0.048^{* \star *}$ & 0.041 & 0.034 & & & & \\
\hline & $(0.014)$ & $(0.016)$ & $(0.025)$ & $(0.025)$ & & & & \\
\hline \multirow[t]{2}{*}{ SC/ST Household*Pradhan reserved for SC/ST } & & $0.071^{* *}$ & $0.071^{* *}$ & $0.064^{* *}$ & & & & \\
\hline & & $(0.031)$ & $(0.031)$ & $(0.032)$ & & & & \\
\hline \multirow[t]{2}{*}{ SC/ST Household*Pradhan village } & & & 0.03 & 0.032 & & & & \\
\hline & & & $(0.025)$ & $(0.025)$ & & & & \\
\hline \multirow[t]{2}{*}{ SC/ST Household*GP headquarters } & & & -0.019 & -0.019 & & & & \\
\hline & & & $(0.025)$ & $(0.025)$ & & & & \\
\hline \multirow[t]{2}{*}{ Proportion SC/ST Households } & & & & & -0.007 & -0.017 & 0.041 & $0.077^{*}$ \\
\hline & & & & & $(0.027)$ & $(0.027)$ & $(0.042)$ & $(0.045)$ \\
\hline \multirow[t]{2}{*}{ Pradhan Village } & & & & & -0.02 & -0.026 & $0.048^{* *}$ & $0.044^{*}$ \\
\hline & & & & & $(0.020)$ & $(0.021)$ & $(0.023)$ & $(0.024)$ \\
\hline \multirow[t]{2}{*}{ Pradhan reserved for SC/ST } & & & & & -0.003 & -0.002 & -0.003 & -0.024 \\
\hline & & & & & $(0.012)$ & $(0.013)$ & $(0.039)$ & $(0.039)$ \\
\hline \multirow[t]{2}{*}{ Pradhan Village*Pradhan reserved for SC/ST } & & & & & -0.003 & -0.008 & 0.003 & -0.002 \\
\hline & & & & & $(0.028)$ & $(0.030)$ & $(0.051)$ & $(0.052)$ \\
\hline \multirow[t]{2}{*}{ GP headquarter } & & & & & -0.003 & -0.007 & $0.041^{*}$ & 0.02 \\
\hline & & & & & $(0.012)$ & $(0.014)$ & $(0.023)$ & $(0.025)$ \\
\hline Controls & no & no & no & yes & no & yes & no & yes \\
\hline Fixed effects & village & village & village & village & block & block & block & block \\
\hline Observations & 4059 & 4059 & 4059 & 4059 & 193 & 174 & 395 & 366 \\
\hline R-squared & 0.1 & 0.11 & 0.11 & 0.11 & 0.43 & 0.46 & 0.67 & 0.68 \\
\hline
\end{tabular}

Notes: The dependent variable in columns (1)-(4) is a dummy variable which equals one if the household's house or toilet was built under a government scheme or if it received a private water or electricity connection via a government scheme since the last GP election. The dependent variable in columns (5)- (6) is the village fixed effect from column (4) regression (excluding the constant). The dependent variable in columns (7) - (8) is an index of whether GP undertook any construction or improvement activity on roads, drains, streetlights and water sources after the last GP election. The SC/ST Household dummy equals 1 for SC/ST households. The Pradhan village dummy equals one if the Pradhan resides in the given village. The GP headquarter dummy equals 1 if the GP

headquarter is located in the village. Individual controls included are dummies for if household is Muslim and Christian, household size, age, literacy and occupation of household head and whether it is the household of an elected panchayat official (alone and interacted with dummy for being a SC/ST household. Village controls included are proportion of landless households, log total village population, log village area, proportion of irrigated land, village literacy rate, distance from nearest town, and daily male agricultural wage rate.

All village controls except for the agricultural wages are from 1991 Census of India. Agricultural wages are from survey data. Variation in sample Robust standard errors in brackets. * significant at $10 \%$; ${ }^{\star *}$ significant at $5 \%$; ${ }^{* * *}$ significant at $1 \%$ 